$\$$

\title{
Prevalence and factors associated with obesity amongst employees of open-cast diamond mine in Namibia
}

\author{
Desderius Haufiku, Hans J Amukugo* \\ Lecturers, School of nursing, Faculty of health Sciences University of Namibia \\ *Corresponding author E-mail: hdesderius@unam.na
}

\begin{abstract}
The study investigated the prevalence and factors associated with obesity amongst employees of Pocket Beaches mine. Obesity rates are increasing at an alarming rate worldwide; 1.2 billion people worldwide are overweight of which 300 million are clinically obese. Of concern, is that obesity is a risk factor for many diseases, including hypertension, diabetes and other forms of cancers. Although there are several mine workers who on reporting to occupational health services for minor ailment are found to be overweight or obese, we are not certain about the extent with the problem. The health risk associated with obesity could cause a big loss to NAMDEB in terms of care cost, low productivity and absenteeism.

The aim of this study was to investigate the prevalence and determinants of obesity amongst NAMDEB employees working at Pocket Beaches diamond mine.a descriptive; cross-sectional study measured the prevalence of obesity and describes the factors that are associated with obesity and overweight.

Study population: NAMDEB employees who were working at Pocket Beaches mine. A simple random sampling technique was used to select participants. Eighty seven employees were selected from 188 total NAMDEB employees working at Pocket Beaches mine. Data was collected through interviews. Anthropometric measurements namely, weight, height and abdominal circumference were collected using a standard protocol.

Data was analyzed using Epi Info 2002. Body Mass Index (BMI) was calculated as kg/m2. Overweight was defined as BMI $=25$ to 29.9 $\mathrm{kg} / \mathrm{m} 2$ and obesity as BMI $\geq 30 \mathrm{~kg} / \mathrm{m} 2$. Waist Circumference $\geq 80 \mathrm{~cm}$ was used to identify central obesity in women and $\geq 90 \mathrm{~cm}$ in men. The frequency of participation in physical activity, barriers to physical activity and food consumption is reported in percent and means. The study found prevalence $42 \%$ overweight and $32 \%$ obesity among employees of NAMDEB. A significant number of participants $48 \%$ never participate in moderate exercise per week. $71 \%$ of participants reported lack of motivation exercising and too tired after work as the major barriers to physical activity. The consumption of fatty foods such as fried chicken and fried meat was common among study subjects. A large number of respondents $79 \%$ eat fried chicken regularly while $74 \%$ eat fried meat regularly. $79 \%$ of participants consumed inadequate fruits and vegetable (one fruit and vegetable per day). The two most mentioned reasons for low fruits and vegetables consumption were lacked of fruits and vegetables in hostel food menu, and $14 \%$ don't like fruits.

This study results revealed a high prevalence of overweight and obesity among employees. There is also low participation in physical activity and inadequate intake of fruits and vegetables among employees. Lack of motivation to exercise and unavailability of fruits and vegetable contributed to unhealthy lifestyles. Appropriate interventions are necessary in order to reduce the high obesity prevalence. Wellness program to promote physical activity should be introduced at Pocket Beaches mine. Management should engage Sodexho (catering company) to increase fruits and vegetables in the employees' menu.
\end{abstract}

Keywords: Obesity, Overweight; Cardiovascular Diseases; Mine Employees; Physical Activity; Nutrition Transition; Urbanization and Globalization; Eating Patterns; Lifestyles; Chronic Diseases.

\section{Introduction}

In the past four decades, obesity has been recognized as the most common risk factor for a number of chronic diseases such as heart diseases, hypertension, stroke, high cholesterol, adult-onset type II diabetes and certain forms of cancers (WHO, 2002; Asfaw, 2006). The World Health Organization (WHO) lists overweight in the top 10 devastating risk factors for high mortality in both developing and developed countries (WHO, 2002). The health consequences range from increased risk of premature death among the affected, to serious chronic diseases that can significantly reduce the quality of life.

Of concern is that obesity rates are increasing at an alarming rate worldwide. Overweight affects 1.2 billion worldwide of which
300 million are clinically obese (WHO, 2003). In developed countries like the USA, the prevalence of overweight is as high as $60 \%$ (Worley, 2006). Meanwhile more than $30 \%$ of the population in Latin America, the Caribbean, Middle East and Northern Africa are overweight (WHO, 2002).

In Southern Africa, obesity is also a major public health problem along with HIV/AIDS and malnutrition. It is also apparent that in developing countries obesity and malnutrition co-exist (Puoane et al, 2002). The South African Demographic and Health Survey (1998) reported a $29 \%$ and $56 \%$ prevalence of overweight in men and women respectively and $9 \%$ and $29 \%$ prevalence of obesity in men and women respectively (Puoane et al, 2002). In addition, a $17 \%$ prevalence of overweight, including obesity has been report- 
ed among young people aged 13-19 years, with higher prevalence in girls 25\% than in boys $7 \%$ (Kara, 2004).

Although there are no statistics on obesity in Namibia, obesity is now increasing the risk and development NCDs especially type 2 diabetes and hypertension (New Era, 27 March 2007; WHO, 2002). Based on statistics from WHO country and regional data (2006) Namibia had 25000 diabetic patients in 2003. It is projected that the number would increase to 60000 by the year 2030 .

WHO worldwide report (2002) suggests that about $60 \%$ of diabetes globally can be attributed to overweight and obesity. Meanwhile, hypertension, which is highly associated with obesity, was reported in Ministry of Health and Social Services (MOHSS) health report of 2003 as one of the most common noncommunicable diseases in Namibia. During the first nine months of 2002 alone over 10000 new cases of hypertension were diagnosed, of which 4000 patients were admitted to hospitals due to hypertension (MOHSS, 2003).

Obesity is now recognized to be partly a consequence of individual lifestyle, in part the result from poor diet (over-nutrition) and lack of physical activity (Opie, 1995). Most Namibians are known for their love of red meat and fatty foods compared to healthier alternatives such as chicken, fish and vegetables (O'Keefe, Rund, Marot, Symmonds\& Berger, 1988). Factors associated with overweight and obesity includes unhealthy lifestyle such as eating the foods rich in animal fats and low in fibre and lack of exercise (Balk, K., Owen, N., Salmon, J., Bauman, A \& Gore, C.J, 2001) These factors are consequences of economic development, modernization, urbanization and globalization (Vorster, Bourne, Venter \&Oosthuizen, 1999; WHO, 2003). Namibia has seen high rates of urban population growth after it attained independence in 1990 At the current rate of urban population growth, it is estimated that $43 \%$ of the population of Namibia would be urbanized, with about 1 million people living in urban places by year 2006, and $50 \%$ by 2010 (Office of the President, 2004).

High prevalence of obesity was also found among employees at one of the South Africa diamond mine (Standler, 2006). The prevalence was $45 \%$ and $32 \%$ among females and males respectively. Obese individuals were found to have low productivity, more susceptible to injuries at work with increased absenteeism (Soteriades et al., 2005; Dias et al., 2003). All these factors had a significant cost to the organization.

However, it has been recognized that several factors played an important role in the increased prevalence of obesity in the workforce. These factors include changes in dietary habits, lack of physical activity in leisure time and certain working condition such as work that requires less labour (Dias, Wolmarans, Laubscher\&Schutte, 2003). It is also worth noting that certain occupations such as machine operators, clerical work and any other job that require someone to work seated can put employees at risk of gaining more weight. Popkin (2001) pointed out that the use of machinery; office bound work and automation together with the phasing out of physically demanding tasks have contributed significantly to the increase in body weight among the working class due to low energy expenditure. This, however, has negative health and employment outcomes in the workforce, including lower productivity and poor job performance.

\section{Aim and objectives of the study}

Aim of the study was to investigate the prevalence and determinants of obesity amongst NAMDEB employees working at Pocket Beaches diamond mine. The objectives of the study were to:

- Assess the prevalence of overweight and obesity amongst Pocket Beaches mine employees.

- Describe the socio-demographic factors associated with obesity among mine employees.

- Determine the level of participation in physical activity among mine employees.

- Assess the barriers to the participation in physical activity among mine employees.
- Assess employee's consumption of fruits and vegetables, fat food and sweetened drinks.

\section{Methods}

This is a descriptive, cross-sectional study design, measuring the prevalence of obesity and describing factors that are associated with obesity and overweight. The study population consists of total number of 188 NAMDEB and contractors' employees who are working at Pocket Beaches diamond mine.

Simple random sampling procedure was used in order to give every employee an equal chance of participating in the study. The researcher obtained a complete list of all employees from the Value Center Leader (VCL) office. All employees were then allocated a number. To select those who were to be included in the sample, numbers were randomly drawn from a small box; those whose numbers were chosen were required to voluntary participate in the study. In the case of selected employees who declined to participate in the study, other randomly selected employees complying with the sample criteria replaced them. The same procedure was followed if selected employees resigned, transferred or were fired during the study period.

The study expected the obesity prevalence to be $35 \%$ (thus expected proportion $\mathrm{p}=0.35$ ) required precision $\mathrm{q}=1-0.35=0.65$, $\mathrm{d}=0.1$ (i.e. $95 \% \mathrm{CI}$ ). Calculations were as follow: $\mathrm{n}=1.96 \times 1.96$ x0.35 x $0.65 / 0.1 \times 0.1=87$. Therefore 87 participants (i.e. $95 \%$ statistical precision) were randomly selected from total number of 188 total permanent employees of Pocket Beaches Mine. The inclusion criteria were all employees employed by NAMDEB or contractors working at Pocket Beaches for less than six months, temporary employees and pregnant women were excluded from the sample.

Data collections tools were questionnaires consisted of some structured questions developed by Stadler (2006) that had been previously used in an analytical, cross-sectional study which investigated dietary intake, physical activity and risk for chronic disease of lifestyle among employees at a South African open-cast diamond mine. Some modifications on questionnaire were made to fit this study. The questionnaires were in English; however the investigator translated it in Oshiwambo to make sure the questions were clearly understood by the participants who did not understand English.

For the interview: This study used interviewer-administered questionnaires to collect data. The researcher himself was responsible for individual employee interviews and thus avoided interviewer variation, which could affect data reliability. Data collected includes: Socio-demographic, Anthropometry and Physical activity and dietary patterns and are described as follows;

Socio-demographic: The socio-demographic questionnaire collected basic socio-demographic information such as age, gender, race, marital status, highest education level, occupational category, department and salary grading.

Anthropometry: Weight was determined to the nearest $0.1 \mathrm{~kg}$ by using a standard clinic scale (Sunbeam) with maximum weight of $130 \mathrm{~kg}$. Each participant was weighed wearing light clothing without shoes. The scale was calibrated regularly between measurements.

Height was measured using metal measuring tape, secured against flat wall and flat headboard positioned at right angle to the wall for collect reading.. Each participant was requested to stand barefooted with back and legs straight and back of the head placed against the wall. Measurements were then taken in centimeters to the nearest $0.1 \mathrm{~cm}$.

A flexible tape measure was used to take measurements of waist circumference. Waist circumference was measured to the nearest $0.1 \mathrm{~cm}$ at the smallest area below the rib cage and above the umbilicus. All measurements were taken twice per participant, and the average reading was recorded.

Physical activity and dietary patterns: To examine physical activity level and dietary patterns of the study participants, face-to face 
interviews were conducted using structured questionnaires. Participants were required in the questionnaire to provide information on three components of physical activity such as exercise, occupational physical activity and leisure-time physical activity. The number of days and duration of exercises per week and barriers of physical activity were asked. Participants were asked to state the frequency with which they consume the following: fruits and vegetables, fatty foods and sweetened drinks. In addition, participants were asked to state the amounts of sugar used in tea/ coffee.

To ensure validity of data collected, a pilot test was done on random sample of seven participants with similar characteristics to the sample population. One representative from each occupational category was included in the pilot study. All ambiguous questions identified during the pilot study were subsequently rephrased and clarified according to the responses and suggestions received by the pilot study participants. The measurements of weight, height and waist circumference were repeated twice on each participant, and the average reading was recorded. This process was done to eliminate inconsistencies. The random sampling method used in this study minimizes any form of bias such as selection bias that can influence the validity of the study. In this study, every employee was given an equal chance to be selected for participation in the study.

Weight and height were used to calculate the body mass index (BMI) of participants according to WHO formula as follows, Body mass index = weight $(\mathrm{kg})$ divided by square of height in (m).The The subject was then classified according to the WHO classification as having underweight (BMI $<18.5 \mathrm{~kg} / \mathrm{m} 2$ ), normal weight (BMI $18.5-24.9 \mathrm{~kg} / \mathrm{m} 2$ ), overweight (BMI $25-29.9$ $\mathrm{kg} / \mathrm{m} 2$ ) and obese (BMI $\geq 30 \mathrm{~kg} / \mathrm{m} 2$ ). A waist circumference measurements equal to or above $94 \mathrm{~cm}$ (action level 1) and 102 $\mathrm{cm}$ (action level 2) for men and equal to or above $80 \mathrm{~cm}$ (action level 1) and $88 \mathrm{~cm}$ (action level 2) for women, was used as cut-off points to determine abdominal obesity as adopted by WHO (2000). According to WHO (2000) a waist circumference at action level 1 means abdominal overweight while action level 2 means abdominal obesity.

Socio-demographic, anthropometric, physical activity and dietary patterns data was captured electronically with Microsoft Excel and data was analyzed by the researcher using Epi Info Version 3.3.2 (a database and statistics software program). Means and standard deviation (SD) were calculated for all continuous variables. The association between obesity and socio-demographic variables were analyzed via the ANOVA test. The level of significance for all statistical tests was set at $\mathrm{p}$-value $<0.05$.

The frequency distribution of physical activity, barriers to physical activity and dietary patterns were analysed and reported in percentage.

This study was approved by members of Pocket Beaches mine management. The UWC Faculty Research and Ethics Committee approved the research protocol. All participants were given information sheets explaining the purpose of the study; that participation in the study was voluntary and that participants could withdraw at any stage. No identification information was required on questionnaires to ensure participants confidentiality. Participants were ensured that data collected from the study would only be used for research purposes and that only the researcher would have access to the data. Participants were requested to sign informed consent forms before data collection.

\section{Results}

\subsection{Socio-demographics}

The sample included 80 males (92\%) and 7 females (8\%) subjects, Table 1 displays socio-demographic characteristics of the sample. Sixty eight $(78 \%)$ of the participants were blacks, while sixteen $(18 \%)$ of the participants were coloured and three $(3 \%)$ were whites. Majority of participants were of the age group of 30-39, 35 (40\%), 25 (29\%) were of age group of 40-49 and 20 (23\%) were of age group of 20-29, whereas $5(6 \%)$ were of age 50-59 and relatively small number fall under age group of 18-29, $2(2 \%)$. Forty six $(53 \%)$ were unmarried and thirty nine $(45 \%)$ were married. Twenty one (24\%) had tertiary education, $44(51 \%)$ had grade 11 to 12 while $1(1 \%)$ had no schooling.

\subsection{Occupational data}

The sample comprised of $32(37 \%)$ participants from the mining department, $22(25 \%)$ from metallurgy, $16(18 \%)$ of participants were from engineering, Barlows $6(7 \%)$ while $5(6 \%)$ and $3(3 \%)$ participants were from Dredge and Security's departments respectively. The largest number of participants were NAMDEB employees $80(92 \%)$ and $7(8 \%)$ were contractors. The occupational categories representing the sample population included mostly operators $48(55 \%)$ comprising of machines and metallurgy operators with a smaller representation from the other occupational categories. With regards to salary grading, according to Patterson band, the majority of the participants $48(55 \%)$ were from the Bband with a significant number from C-band 24 (27\%), which is the highest salary level for the participants.

Table 1: Socio-Demographic Characteristics of the Sample Population (N $=87$ )

\begin{tabular}{lll}
\hline Demographic variable & $\begin{array}{l}\text { Gender } \\
\text { Male n }(\%)\end{array}$ & Female n $(\%)$ \\
\hline Race & $61(70 \%)$ & $7(8 \%)$ \\
Black & $16(18 \%)$ & $0(0 \%)$ \\
Coloured & $3(4 \%)$ & $0(0 \%)$ \\
White & & \\
Age & $19(22 \%)$ & $3(4 \%)$ \\
$18-29$ & $32(37 \%)$ & $3(4 \%)$ \\
$30-39$ & $24(28 \%)$ & $1(1 \%)$ \\
$40-49$ & $5(6 \%)$ & $0(0 \%)$ \\
$50-59$ & & \\
Marital status & $42(48 \%)$ & $4(6 \%)$ \\
Unmarried & $36(41 \%)$ & $3(3 \%)$ \\
Married & $1(1 \%)$ & $0(0 \%)$ \\
Divorced & $0(0 \%)$ & $0(0 \%)$ \\
Separated & $1(1 \%)$ & $0(0 \%)$ \\
Living together & & \\
Education & $19(22 \%)$ & $2(2 \%)$ \\
Tertiary education & $41(47 \%)$ & $3(3 \%)$ \\
Grade 11 to 12 & $11(13 \%)$ & $2(2 \%)$ \\
Grade 8 to 10 & $8(9 \%)$ & $0(0 \%)$ \\
Grade 7 and below & $1(1 \%)$ & $0(0 \%)$ \\
No Schooling & & \\
\hline
\end{tabular}

\subsection{Anthropometry}

The age specific means and standard deviation (SD) of four anthropometric variables shows the following trends: generally study had shown that the total study population was overweight (mean BMI 27.6, SD 5.23), the mean BMI was higher for age group of 50-59 years old than other age groups (mean BMI $33.2 \mathrm{~kg} / \mathrm{m}^{2}$ ). There was no significant differences in height of participants among the age groups $(\mathrm{p}=0.52)$. Results also show that age group of 50-59 years old had increased abdominal obesity (mean WC $113.6 \mathrm{~cm}$ ) while the younger age group 18-29 years old had normal waist circumference (mean WC $87.5 \mathrm{~cm}$ ). Those in the age group of 50-59 were heavier than the rest of age groups (mean weight $105.40 \mathrm{~kg}$ ), as indicated in table 3 .

\subsection{BMI classification of total study population}

Height, weight and waist circumference were indicators used to determine whether population was obese, overweight, underweight or had normal weight. The BMI of the respondents ranged between 18 and $45 \mathrm{~kg} / \mathrm{m}^{2}$. The mean BMI of the respondents was $27.6 \mathrm{~kg} / \mathrm{m}^{2}$ with a SD of 5.23 . Of the total study population, twenty eight $(32 \%)$ of the study participants were classified as obese $\left(\mathrm{BMI} \geq 30 \mathrm{~kg} / \mathrm{m}^{2}\right)$, thirty six $(42 \%)$ as overweight (BMI>24.9 $<30 \mathrm{~kg} / \mathrm{m}^{2}$ ), twenty one $(24 \%$ ) as normal weight (BMI $18.6-24.9$ 
$\mathrm{kg} / \mathrm{m}^{2}$ ), while three (3\%) as morbidity obese (BMI $\left.\geq 40 \mathrm{~kg} / \mathrm{m}^{2}\right)$ and two $(2 \%)$ were classified as underweight $\left(\mathrm{BMI}<18.6 \mathrm{~kg} / \mathrm{m}^{2}\right.$ (Figure 1).

Table 2: Anthropometric Value by Total Study Population and by Age ( $\mathrm{N}$ $=87$ )

\begin{tabular}{|c|c|c|c|c|c|c|}
\hline Variable & $\begin{array}{l}\text { Total } \\
\text { popula- } \\
\text { tion } \\
\text { Mean } \\
\text { (SD) }\end{array}$ & $\begin{array}{l}18-29 \\
(\mathrm{n}=22 \\
) \\
\text { Mean } \\
(\mathrm{SD})\end{array}$ & $\begin{array}{l}30-39 \\
(\mathrm{n}=35 \\
) \\
\text { Mean } \\
(\mathrm{SD})\end{array}$ & $\begin{array}{l}40-49 \\
(\mathrm{n}=25) \\
\text { Mean } \\
(\mathrm{SD})\end{array}$ & $\begin{array}{l}50-59 \\
(\mathrm{n}=5) \\
\text { Mean } \\
(\mathrm{SD})\end{array}$ & $\begin{array}{l}\text { P- } \\
\text { Val- } \\
\text { ue }\end{array}$ \\
\hline BMI & $\begin{array}{l}27.6 \\
(5.23)\end{array}$ & $\begin{array}{l}25.59 \\
(4.81)\end{array}$ & $\begin{array}{l}26.6 \\
(4.82)\end{array}$ & $\begin{array}{l}29.80 \\
(4.55)\end{array}$ & $\begin{array}{l}33.20 \\
(6.76)\end{array}$ & 0.00 \\
\hline Height & $\begin{array}{l}1.74 \\
(.07)\end{array}$ & $\begin{array}{l}1.73 \\
(.07)\end{array}$ & $\begin{array}{l}1.75 \\
(.08)\end{array}$ & $\begin{array}{l}1.73 \\
(.05)\end{array}$ & $\begin{array}{l}1.77 \\
(.06)\end{array}$ & 0.52 \\
\hline $\begin{array}{l}\text { Waist cir- } \\
\text { cumference }\end{array}$ & $\begin{array}{l}95.9 \\
(14.02)\end{array}$ & $\begin{array}{l}87.5 \\
(10.50 \\
)\end{array}$ & $\begin{array}{l}93.7 \\
(12.00 \\
)\end{array}$ & $\begin{array}{l}102.8 \\
912.02 \\
)\end{array}$ & $\begin{array}{l}113.6 \\
(20.80 \\
)\end{array}$ & 0.00 \\
\hline Weight & $\begin{array}{l}85.2 \\
(16.56)\end{array}$ & $\begin{array}{l}77.8 \\
(15.06 \\
)\end{array}$ & $\begin{array}{l}83 \\
(15.22 \\
)\end{array}$ & $\begin{array}{l}90.7 \\
(15.30 \\
)\end{array}$ & $\begin{array}{l}105.4 \\
0 \\
(17.09 \\
)\end{array}$ & 0.00 \\
\hline
\end{tabular}

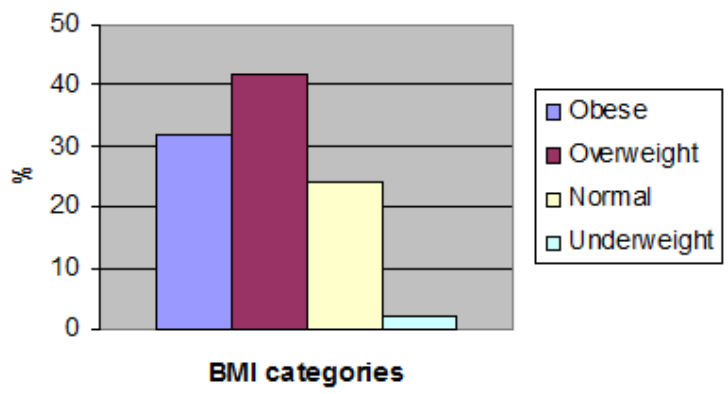

Fig. 1: BMI Classification of Total Study Population $(\mathrm{n}=87)$.

\subsection{BMI classification by age}

Obesity was more prevalent $(80 \%)$ in the $50-59$ age group while overweight was more prevalent (46\%) in the age group of 30-39, meanwhile underweight was (4\%) in the age group of 18-29. A significant difference was found between the mean BMI of the four age groups ( $\mathrm{p}$-value 0.00 ).

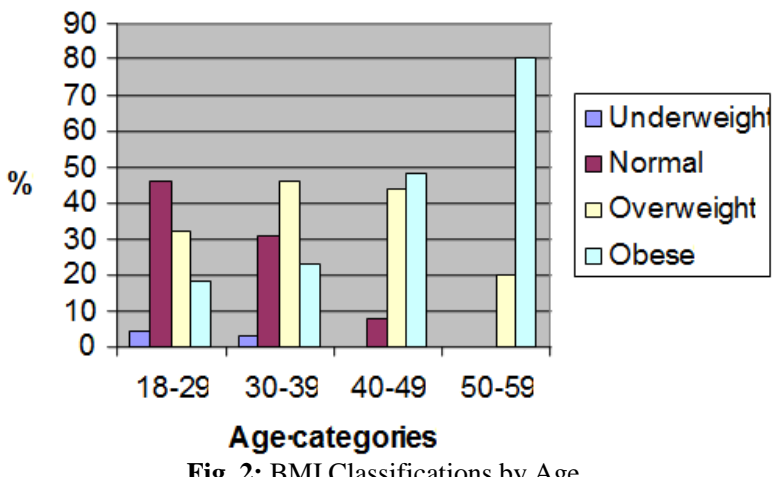

\subsection{Prevalence of obesity and overweight by depart- ments.}

Obesity was most prevalent $(67 \%)$ among the security department while overweight was most prevalent $(80 \%)$ among dredge employees

\subsection{Prevalence of abdominal obesity of the total study population and by age}

A waist circumference measurement equal to or above $94 \mathrm{~cm}$ (action level 1) and $102 \mathrm{~cm}$ (action level 2) for men and equal to or above $80 \mathrm{~cm}$ (action level 1) and $88 \mathrm{~cm}$ (action level 2) for women, as adopted by the WHO (1995), was used as cut-off points to determine abdominal overweight and abdominal obesity among the participants. A waist circumference of $\geq 102 \mathrm{~cm}$ in men and $\geq 88 \mathrm{~cm}$ in women exhibit a high risk to chronic diseases of lifestyles. The waist circumference of study population ranged between $66 \mathrm{~cm}$ and $150 \mathrm{~cm}$, the mean waist circumference was 95.93 with a SD of 14.02 . Twenty six $30 \%$ of participants had waist circumference equal to or above $102 \mathrm{~cm}$ (action level 2), while $29 \%$ had abdominal overweight (WC $>94 \mathrm{~cm}$ action level 2 ), as indicated in figure 4 . The age group of 50-59 had increased prevalence of central obesity $60 \%$ compared to much lower prevalence $9 \%$ in the age group of 18-29. Figure 5 illustrates the waist circumference classification by age group.

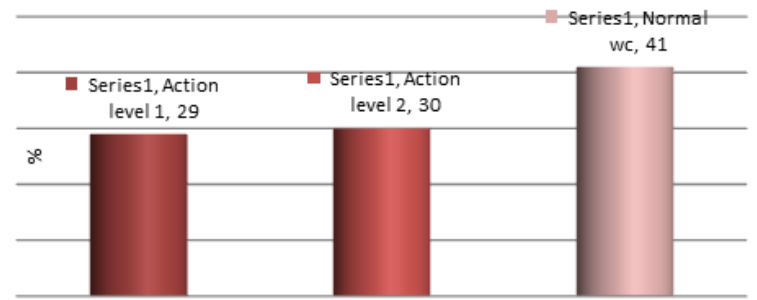

Fig. 4: Percentages Distribution of Abdominal Obesity $(\mathrm{N}=87)$.

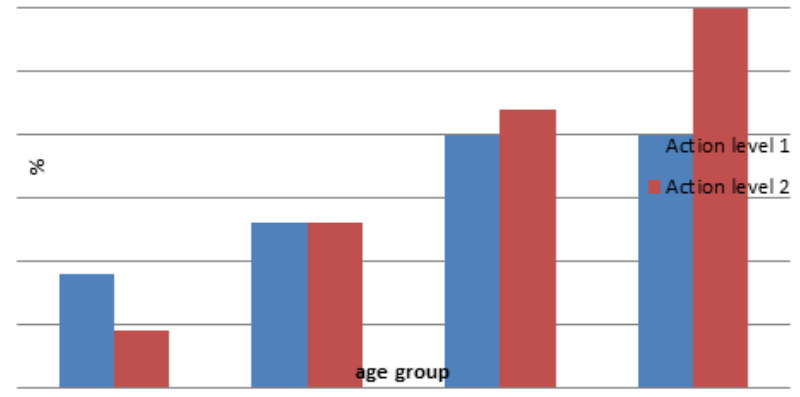

Fig. 5: WC Classification by Age.

\subsection{Physical Activity}

The habitual physical activity referred to three components of physical activity which includes daily exercise, occupational physical activity and leisure time physical activity.

\subsection{Levels of participation in daily exercises by partici- pants}

Participants were asked to report frequency of participation in moderate exercises per week (exercises in which they find themselves running out of breath and sweating). Forty two (48\%) of participants never exercise per week, nineteen (22\%) exercise 2-3 times a week while fourteen (16\%) exercise once a week and only six $(7 \%)$ exercise more than 5 times a week. Those who exercise for more than 5 times a week had low mean BMI $\left(25.3 \mathrm{~kg} / \mathrm{m}^{2}\right)$ compared to those who never exercise per week (mean 28.7 $\mathrm{kg} / \mathrm{m}^{2}$ ) and there was significant differences $\mathrm{p}-0.04$.

Forty five $(52 \%)$ of participants had less than five minutes of moderate exercise, twenty two (25\%) exercise $15-30$ minutes, ten (12\%) exercises for 5-15 minutes meanwhile three (3\%) exercise for more than 45 minutes ( Figure 6). 


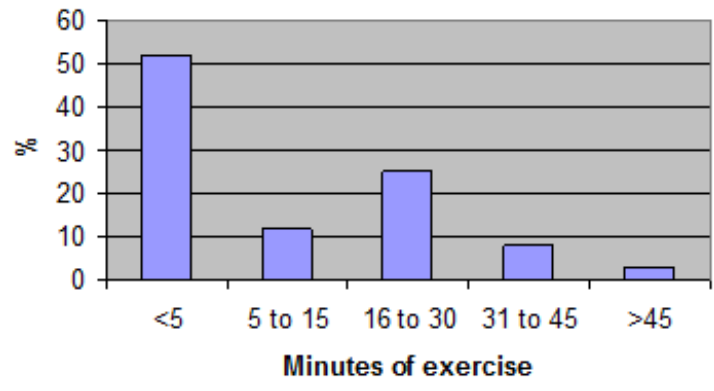

Fig. 6: Duration of Exercise by Total Study Population (N=87).

\subsection{Scope of physical work}

Participants were asked to describe the degree of physical labour related to their occupation by selecting one of three possible options, as per the classification of the Centre for Diseases Control (Takao, Kawakami \&Ohtsu, 2003).

Occupational physical activity was classified into three categories such as light, moderate and heavy. A light degree of physical labour was classified as no hard physical labour, a moderate degree of physical labour was classified as 1-4 hours of physical labour and heavy degree of physical labour was classified as more than 5 hours of physical labour per day. Thirty nine $(45 \%)$ had light, twenty nine $(33 \%)$ had moderate and nineteen $(22 \%)$ had a heavy occupational physical labour, as indicated in Figure 7. There were slight BMI mean differences $\left(0.9 \mathrm{~kg} / \mathrm{m}^{2}\right)$ of those with a heavy degree of physical labour and those with a light degree of physical labour.

Respondents were asked to indicate the number of hours they spend sitting at work. Forty $(46 \%)$ spend more than four hours sitting, twenty five (29\%) spend 1-2 hours, whereas eight (9\%) spend less than 1 hour sitting at work.

\subsection{Leisure physical activity}

Forty four $(51 \%)$ respondents watch television only sometimes (three days per week) on their leisure time, twenty (23\%) watch television often (more than three days per week) during leisure time, eleven (13\%) watch television very often whereas two (2\%) never watch television during leisure time.

Respondents were asked to indicate the number of hours they spend watching television. Thirty seven $(43 \%)$ spend $1-2$ hours watching television, twenty two (25\%) spend less than 1 hour, whereas seventeen spend 2-3 hours in front of television during leisure time.

Six $(7 \%)$ respondents walk or jog often during leisure time while thirty five $(43 \%)$ never exercise during their leisure time (Figure 8 ). Those who walk or jog during leisure time were forty eight $(55 \%)$ for only less than five minute, twenty $(23 \%)$ walk or jog for 5-15 minutes, while thirteen (15\%) walk or jog for 15-30 minutes. Those who walk or jog regularly during leisure time had low mean BMI $\left(25.1 \mathrm{~kg} / \mathrm{m}^{2}\right)$ compared to those who never participated in physical activity during leisure time (mean BMI $28.8 \mathrm{~kg} / \mathrm{m}^{2}$ ).

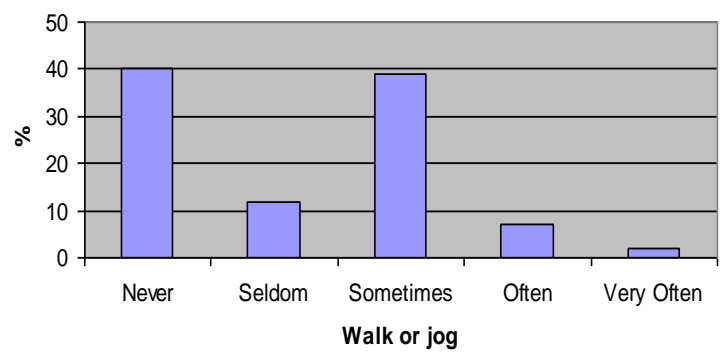

Fig. 8: Prevalence of Exercise during Leisure Time.

\subsection{Barriers to physical activity participation}

The three most frequently reported barriers to physical activity by the sample population lack motivation to exercise / too lazy/ cannot get started by $33 \%$, leave too early for work/ get home too late by $22 \%$ and too tired after work/ haven't got the energy by $21 \%$ (Figure 9). Too tired after work/ haven't got energy was reported as the barrier to participation in physical activity by (71\%) women and $13(16 \%)$ men. Lack time due to work demand was reported by $16(20 \%)$ men.

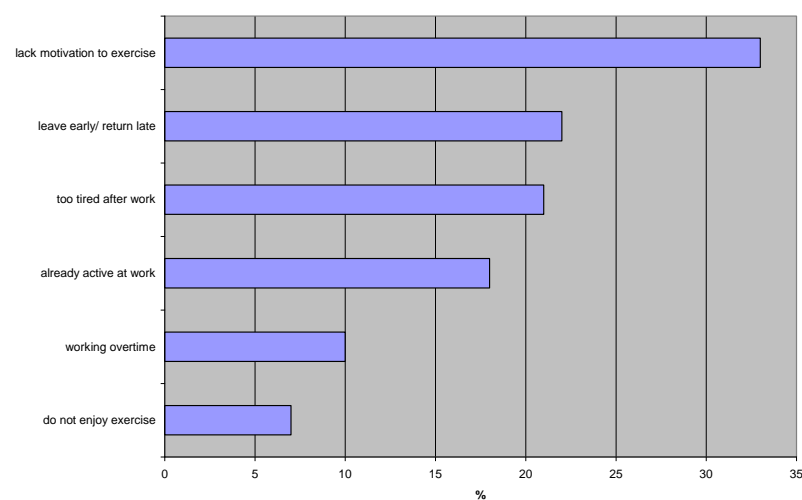

Fig. 9: Barriers to Physical Activity.

\subsection{Dietary intake}

\subsubsection{Frequency of eating fruits and vegetables per day}

When respondents were asked the number of fruits and vegetables, they ate per day, sixty nine (79\%) ate one fruit and vegetable per day, ten $(12 \%)$ of respondents ate 2-3 fruits and vegetables per day whereas seven (8\%) never eat fruits and vegetables (Figure 10). No significant differences were found between mean BMI of participants and fruits and vegetables consumption per day ( $\mathrm{p}$-value $0.93)$.

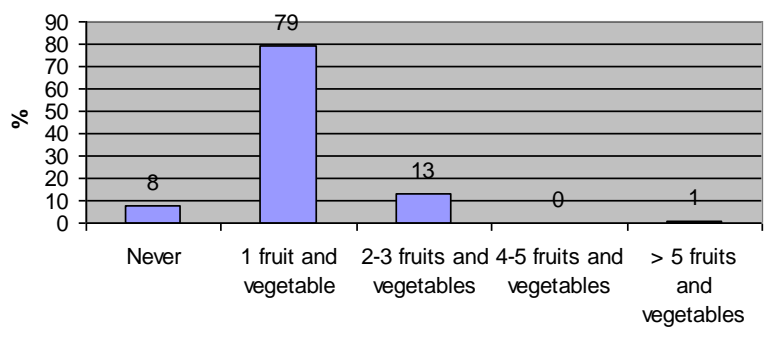

Fig. 10: Frequency of Eating Fruits and Vegetables per Day.

\subsubsection{Main reasons for low consumptions of fruits and vege- tables}

The two most frequently mentioned reasons that prevent respondents from eating enough fruits and vegetables were, not enough fruits and vegetables in Sodexho menu (the company catering for employees at Pocket Beaches mine) by $71 \%$ and do not like fruit and vegetable by $14 \%$ (Figure 11).

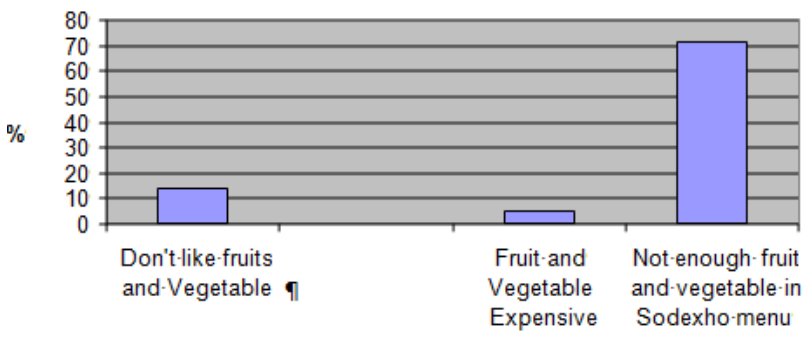

Fig. 11: frequency of barriers to eat fruit and Vegetable. 


\subsubsection{Frequency of eating fried chicken/ other meat}

A Significant number of respondents 69 (79\%) ate fried chicken regularly, while 8 (9\%) never have chicken. Meanwhile 69 (74\%) of people ate another fried meat regularly, while $8(9 \%)$ don't ate another fried meat. This had indicated that high number of employees consumed fatty food.

\subsubsection{Frequency of trimming fat from meat before cooking}

The majority of respondents $36(41 \%)$ do not trim fat from meat before cooking, while $20(23 \%)$ always trimmed fat from meat before cooking, whereas $31(36 \%)$ trimmed fat from meat before cooking only sometimes.

\subsubsection{Frequency of drinking sweetened drinks/ unsweetened drinks}

Respondents were asked the frequency of drinking sweetened drinks such as cool drinks and fruits juices, 44 (51\%) drank sweetened drinks always when thirsty. Again respondents were asked to report the frequency of drinking unsweetened drinks such as water, $45(52 \%)$ drink unsweetened drinks sometimes (not regularly), $24(28 \%)$ always (every day) drink unsweetened drinks, whereas 18 (21\%) don't drink unsweetened drinks at all (Figure 13).

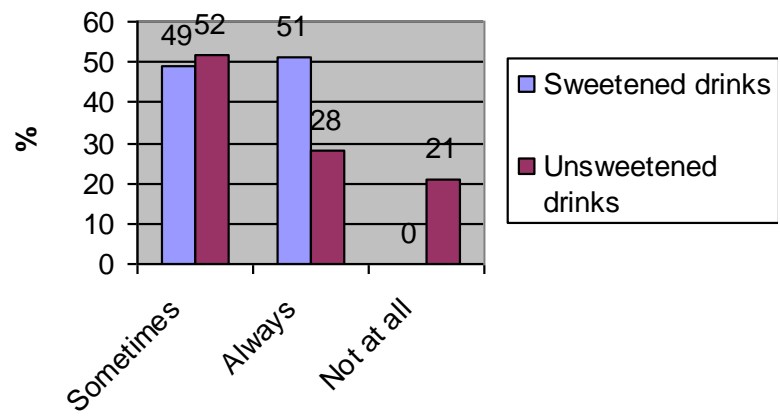

Fig. 13: Frequency of Drinking Sweetened and Unsweetened Drinks.

\subsubsection{Number of teaspoons used in tea or coffee}

Majority of respondents $50(58 \%)$ used 2-3 teaspoon of sugar in tea or coffee, while a significant number $24(28 \%)$ used 4 and above teaspoon in tea or coffee.

\section{Discussion}

This study investigated the prevalence and factors associated with overweight and obesity among NAMDEB employees working at Pocket Beaches mine in Oranjemund-Namibia.

This study has found prevalence $42 \%$ overweight and $32 \%$ obesity among employees of NAMDEB. The prevalence of overweight in this study was higher than the prevalence reported by Stander (2006) among mineworkers at a South African open-cast diamond mine which was $40 \%$. However, obesity prevalence in this study was marginally low $30 \%$ compared to $34 \%$ reported by Standler. The high prevalence of overweight and obesity in this study reflect that obesity is becoming a major health problem in developing countries. South African Demographic and Health Survey (1998) reported a $56 \%$ prevalence of obesity among women and $29 \%$ in men (Puoane et al 2002). It had been suggested that increasing urbanization and rise in socio-economic status in developing population would increase their proneness to obesity (Bourne, Lambert \&Steyn, 2002).

The earlier beliefs that obesity is a disease of rich countries need to be denounced, and appropriate interventions need to be implemented in developing countries as a matter of urgency. Obesity can have a considerable impact on work capacity and fitness for duty among employees (Soteriades et al., 2005). This study used BMI to measure obesity; therefore, not investigated if the high prevalence of overweight and obesity was linked to high muscular mass or high body-fat mass. In this study $33 \%$ of employees were involved in manual labour, which would influence their muscularity.

Despite being shown to be a reliable indicator of obesity and overweight, BMI does not make a clear difference between overweight resulting from fat mass and that resulting from muscular mass (Lee \&Nieman, 2003). The The prevalence of obesity in this study was found to increase with age. For example, $80 \%$ of the 50 59 year old age group was obese compared to $18 \%$ in $18-29$ year old age group. This result is consistent with previous findings that obesity in adults increases up to the age of 65 after which it decreases (Grujic, Martinov-Cvejin, Ac-Nikolic\&NiciforovicSurkovic, 2005). Increased obesity rate in adults appears to result from decreased physical activity and resting metabolic rate in adulthood. Adult experience $20 \%$ decrease in energy expenditure compared with younger people (Beers, 2000). The age-related reductions in resting metabolic rate result from several changes within the body during adulthood. Those changes include reduced muscle tone and strength of muscle contraction, and certain hormones (Beers \& Jones, 2000).

Furthermore, $60 \%$ of the age group of 50-59 years old had an increased waist circumference (action level 2) compared to $9 \%$ in age group of 18-29 years old, indicating a high prevalence of central obesity among adult employees. This is a worrying situation because central obesity is highly associated with risk of chronic diseases of lifestyle than peripheral obesity. Individuals with abdominal obesity are more likely to develop chronic diseases such as CVD, type 2 diabetes, hypertension and stroke (Donahue et al., 1987; WHO, 2003).

Results for daily physical activity showed that most (48\%) of the Pocket Beaches mine employees never exercise per week with only a small proportion (7\%) exercising more than 5 times a week. Furthermore, less time is spent on exercises. In this study, $52 \%$ of the participants exercised for less than 5 minutes, this being far below 30 minutes exercises regime that is recommended by WHO (2003). These findings showed a low level of exercise thereby indicating that physical inactivity is a problem, and employees need to be encouraged to exercise at least for more than three days per week as recommended by WHO. Physical inactivity in the mine employee was associated with obesity in this study. Study shown that employees who participated in physical activity during leisure had low mean BMI $(25.1 \mathrm{~kg} / \mathrm{m} 2)$ compared to those who never exercised on leisure (mean BMI $28.8 \mathrm{~kg} / \mathrm{m} 2$ ). Regular physical activity is necessary not only to prevent obesity but also to maintain good emotional and physical health (Centers for Disease Control and Prevention, 2000; WHO, 2003). With regard to occupational physical activity, there was a higher prevalence of low active occupation with $45 \%$ of the participants having low degree of physical activity at work. The possible explanation to low physical labour is possibly caused by the use of labour-saving mechanical devices. Many employees such as machine operators, metallurgy operators and dredge operators are using automated machines. This means employees work required them to spend much time sitting and involved less physical labour. This could be explained by the majority of respondents for this study being employed in sedentary occupation. For example, $56 \%$ of participants worked as security officers, machine operators, management/foremen and clerical. The study findings have shown a significantly low leisure-time physical activity with only $7 \%$ of employees participating in physical activity during leisure time by walking or jogging. This study showed that employees mostly watch television on their leisure time rather than participating in physical activity. For example, $87 \%$ participants reported watching television regularly during leisure time for more than two hours. Watching television is known to be the most inactive behavior next to sleeping; people tend to be totally still and even lie down and tend to snack frequently while watching television (Dietz, 1996) All these has effect on weight gain.

The three most frequently reported barriers to physical activity by participants were lacked of motivation to exercise/too lazy/cannot get started (33\%), leave too early for work/ get home too late 
(22\%) and too tired after work hadn't got energy (21\%). The above mentioned barriers to physical activity are in agreement with the findings of the Canadian Fitness and Lifestyles Research Institute (1996). The Canadian Fitness and Lifestyle Research Institute reported lack of energy, lack of motivation and lack of time as the most important barriers to physical activity participation. South African diamond mineworkers reported that they left too early for work/ get home too late, lack of time due to family commitments and too tired to exercise after work as the most important barriers to physical activity participation (Standler, 2006). In this study $32 \%$ of participants reported lack of motivation/too lazy/ cannot get started as a barrier to physical activity participation. The above mentioned barriers demonstrated that lack of motivation, and too much work prevented employees from engaging in physical activity during leisure time. Booth et al (1997) has also found lack of interest/ motivation and lack of time and working shifts to be barrier to physical activity participation among bluecollar workers. However, in one study done in South Africa, perceptions that loss of weight meant that person was infected with HIV; lack of exercise and relaxation facilities was identified as barriers to physical activity participation (Puoane\&Tsolekile, 2008).

Increased consumption of fruits and vegetables ensure an adequate intake of dietary fiber which can help to displace fats and sugar in the body (Popkin, Horton \& Kim, 2001). WHO (2003) recommends intake of minimum 5 potions of fruits and vegetables per day.

The current study revealed generally low consumption of fruits and vegetable at Pocket Beaches mine. Majority of respondents (79\%) reported that they ate only one fruit and vegetable per day. The low consumption of fruits and vegetables were also reported in a study done in South Africa, which assessed the nutrition and occupational health of employees of the mining industry (Dias et al 2003). According to World Health Report (2003), low fruits and vegetables intake is responsible for high prevalence of obesity and non-communicable diseases worldwide. There is convincing evidence in literature that high consumption of fruits and vegetable can decrease obesity (Gibney\&Voster, 2001). However, in this study there was lacked of association between BMI status and fruit and vegetables consumption. A possible explanation for inability to show association would be that the majority of participants only consumed one fruit and vegetable per day, limiting the variance to detect an effect. The most frequently mentioned barrier to more consumption of fruits and vegetables was lacked of fruits and vegetables in the hostel food menu (71\%) and $14 \%$ did not like fruits and vegetables. Similar barriers to the consumption of vegetables and fruits have been reported elsewhere (Gibney\&Voster 2001; Stockmyer, Kuester, Ramsey \& Dietz, 2000). The South African Food-Based Dietary Guidelines Consumer study highlighted the following barriers: lack of availability of fruits and vegetables, taste preferences and affordability. The result showed that Sodexho, the company catering food for NAMDEB mineworkers does not have enough fruits and vegetables in its menu. This is a worrying situation because there is no canteen at Pocket Beaches mine where employees can buy fruits and vegetable when they did not get enough from hostel kitchen. Therefore availability of fruits and vegetable is a major problem need urgent intervention.

South African Food Based Dietary Guidelines (2001) recommended a moderate fat diet providing less than $30 \%$ of total energy. Increased fat intake especially fat from animal sources is positively associated with obesity, cardiovascular diseases and certain form of cancers such as breast, colon and prostate cancers (Wolmarans\&Oosthuizen, 2001).

The consumption of fatty foods such as fried chicken and fried meat was common among study participants. A large number of respondents $(79 \%)$ eat fried chicken while $(74 \%)$ eat fried meat regularly. Fried food was also found to be a preferred method of preparation in urban black South Africans (Puoane\&Tsolekile, 2008). People associated fried food with civilization and regard those who are using the traditional method of boiling food as backward (Chopra \&Puoane, 2003). Chopra and Puoane (2003) reported reasons for fat consumptions as due to people preferred to fry food because it is quick and fried meat is tastier than boiled meat. Previous survey has established that the amount of fat consumed by mineworkers living at the hostel is more than adequate, if not excessive (Dias et al, 2003). Bourne et al, (2002) reported that fat intake among urban blacks have increased from $16.4 \%$ to $26.2 \%$ of total energy and at the same time carbohydrate intake decreased. Unfortunately this study has not investigated the total fat intake of employees in order to establish if it was at the recommended level.

Furthermore, this study results have indicated that $51 \%$ of employees always drink sweetened drinks when they are feeling thirsty compared to $28 \%$ who always drink unsweetened drinks such as water. The increased intake of sugary drinks can lead to excessive energy intake than the body can use which then be converted into fat (Perbellini, 2004). Drinking unsweetened drinks such as water have been reported to help people to feel fuller and prevent overeating. It is recommended that water intake for men should be 2.9 1/day and 2.2 1/day for women (Bourne \&Searger, The most important findings from this study are the high prevalence of overweight and obesity among employees at Pocket Beaches. The high prevalence of overweight and obesity can be attributed to low physical activity both at work and during leisure time, and low consumption of fruits and vegetables. The population also has a high consumption of refined carbohydrate and fat in the form sweetened drinks and fried food. This can predispose them not only at high risk of developing obesity but some other non-communicable diseases such as diabetes, CVDs and some cancers. Of concern is high prevalence of obesity among older employees 50-59 years old and low physical activity participation of this age group.

\section{Conclusions}

The study investigated the prevalence and factors associated with obesity amongst employees at Namibia open-cast diamond mine. The results revealed a high prevalence of overweight and obesity among employees; older employees have high obesity and overweight rate than the younger counterparts. Obesity and overweight in this study associated with age and occupation. It was found that the physical activity of employees is generally low during work time and on leisure time. The diet of employees is characterized by high intake of fat and low consumption of fruits and vegetables increasing their risk for developing obesity and other noncommunicable diseases. Study identified some barriers to physical activity such as lack of motivation and work related factors such as leave too early and came back too late and tired after work. Meanwhile, barriers to high consumption of fruits and vegetable identified by this study include lack of fruits and vegetables in food served to employees at mine hostel and dislike of fruits and vegetables. There is urgent need for Pocket Beaches mine to develop intervention strategies in order to promote healthy lifestyles and reduce the high prevalence of overweight and obesity among employees. This study recognized its limitation due to small sample size; therefore, the findings cannot be extrapolated to other NAMDEB mine populations.

\section{Recommendations}

All employees should be measured BMI during the preemployment and routinely annual medical examinations. Those with above-normal BMI should be treated accordingly, and those with normal BMI should be counseled to avoid gaining weight. Namded wellness program should engage in educating employees on healthy lifestyles such as increased physical activity, increased intake of fruits and vegetables and reduced intake of saturated fats and sweetened drinks. To promote physical activity among employees, the Namdeb inter-departmental sport events (7-A- side should be held quarterly instead of annually as it now. Although a 
Namdeb inter-departmental sport event well known as (7-A- side was established as a safety campaign, it has a potential to promote physical activity among employees if it is held regularly. Employees should be encouraged to make use of a physical activity centre (gym) which is available at Pocket Beaches hostel.

With regard to diet, there is a need to establish a food committee at Pocket Beaches in order to oversee the food preparation and engage Sodexho in addressing the problem of high fat content in diet and low fruits and vegetables provided to employees. Employee's meals should have low fat, low sugar and high in fibre in order to prevent and reduce obesity and other chronic diseases of lifestyles among employees.

It is recommended that further studies with big sample representing all Namdeb mines should be performed in order to have representative findings of the whole company. In the proposed studies, BMI should be used to determine obesity together with skin fold measurements to distinguish between subjects with a high body muscle mass and high body-fat mass. Another research needs to be undertaken to examine other determinants of obesity, such as total dietary intake, as well as more direct measures of energy expenditure (heart rate and accelerometers) in order to characterize domain and intensity of exercise more accurately. Attempt should also be made to quantify the cost of obesity and other noncommunicable diseases to the organization in order to plan and budget for intervention strategies.

\section{Acknowledgement}

1) Prof ThandiPuoane University of Western Cape

2) Dr Hans J Amukugo University of Namibia

\section{References}

[1] Alberti, G. (2001). Noncommunicable Diseases: Tomorrow's Pandemics. Bulletin of the World Health Organization: vol. 79 no. 10 http://dx.doi.org/10.1006/pmed.1999.0489.

[2] Allison, K.R., Dwyer, J.J. \& Makin, S. (1999). Perceived Barriers to Physical Activity among High School Students. Preventive Medicine 28(6): 608-15.

[3] Asfaw, A. (2006). The Effect of Obesity on Doctor-Diagnosed Chronic Diseases in Africa: Empirical Result from Senegal and South Africa. Journal of Public Health Policy, 27: 250-264. http://dx.doi.org/10.1057/palgrave.jphp.3200089.

[4] Armstrong, N. \&Welsman, J.R. (1997). Physical Activity and Aerobic Fitness. Oxford: Oxford Medical Publication.

[5] Barker, D.J. (1997). Maternal Nutrition, Fetal Nutrition and Diseases in Later Life. Nutrition: 13(9): 807-13. http://dx.doi.org/10.1016/S0899-9007(97)00193-7.

[6] Barsh, G.S, Farooqi, I.S. \&O'Rahilly, S. (2000). Genetics of BodyWeight Regulation. Nature: 404:644-651.

[7] Blanche, M.T., Durrheim, K. \& Painter, D. (2004). Research in Practice: Applied Methods for the Social Science. Cape Town: UCT.

[8] Bourne, L.T., Lambert, E.V. \&Steyn, K. (2002). Where does the Black Population of South Africa Stand on the Nutrition Transition? Public Health Nutrition, 5(1A): 157-62. http://dx.doi.org/10.1079/PHN2001288

[9] Bjaras, G., Ahlbom, A., Alvarsson, M., Burstrom, B., Diderichsen, F. Efendic, S., Grill, V., Haglund, B.J., Norman, A., Persson, P.G., Svanstrom, L., Tillgren, P., Ullen, H. \&Ostenson, C.G. (1997). Strategies and Methods for Implementing a Community-Based Diabetes Primary Prevention Program in Sweden. Health Promotion International: (12):2. http://dx.doi.org/10.1093/heapro/12.2.151.

[10]Booth, M.L., Bauman A., Owen N. \& Gore, C.J. (1997). Physical Activity, Preferred Sources of Assistance, and Perceved Barriers to Increased Activity among Physical Inactive Australians. Prevention Medicine. 26:131-137. http://dx.doi.org/10.1006/pmed.1996.9982.

[11]Boutayeb, A. \&Boutayeb, S. (2005). The Burden of NonCommunicable Diseases in Developing Countries. International Jounal for Equity in Health, 10: 118/1475-9276-4-2.

[12]Canadian Fitness and Lifestyle Research Institute. (June 1996). Barriers to Physical Activity. Bulletin no. 4.

[13]Centre for Diseases Control and Prevention (2000). Guidelines for School and Community Programs. Promoting Lifelong Physical Activity.
[14]Chopra, M. \&Puoane, T. (2003). 'Prevention of Diabetes through Obesogenic World.' Diabetes Voice, 48: 24-26.

[15]Desmond, A.W., Conrad, K.M., Montogomery, A. \& Simon, K.A. (1993). Factors Associated with Male Workers' Engagement in Physical Activity-White Collar vs. Blue Collar Workers. AAOHN Jounal, 41: 73-83.

[16]Dias, B., Wolmaras, P., Laubscher, J.A. \&Schutte, P.C. (December 2003). Nutrition and Occupational Health and Safety in the South African Mining Industry. Safety in Mines Research Advisory Committee (SIMRAC). Thrust 9, SIM020919.

[17]Diepietro, L. (1995). Physical Activity, Body Weight and Adiposity: An Epidemiological Perspective. Exercise and Sport Review, 23: 275 303. http://dx.doi.org/10.1249/00003677-199500230-00011.

[18]Donahue, R.P., Abbot, R.

[19]D., Bloom, E., Reed, D.M. \& Yano, K. (1987). Central Obesity and Coronary Heart Disease in Men. Lancet, 1:821-4.

[20]Faber, M. \& Kruger, H.S. (2005). Dietary Intake, Perceptions Regarding Body Weight Control of Normal Weight, Overweight and Attitudes toward Weight Control of Normal Weight, Overweight, and Obese Black Females in a rural Village in South Africa. Ethnicity and Diseases 15(2): 238-45.

[21]Farooqi, I.S., Yeo, G.S., Keogh, J.M., Aminian, S., Jebb, S.A., Butler G., Cheetham, T. \&O'Rahilly, S. (2000). Dominant and Recessive Inheritance of Morbid Obesity Associated with Melanocortin 4 Receptor Deficiency. J Clin Invest: 106:253-262. http://dx.doi.org/10.1172/JCI9397.

[22]Finkelstein, E., Fiebelkorn, C. \& Wang, G. (2005). The Cost of Obesity among Full-time Employees. American Jounal of Health Promotion, 20(1):45-51. http://dx.doi.org/10.4278/0890-1171-20.1.45

[23]Fu, D., Shao, R. \& van Ommeren, M. (2003). Community-based Intervention for Prevention and Control of Cardiovascular Diseases. Geneva Foundation for Medical Education and Research.

[24]Gibney, M. \&Voster, H. (2001). South African Food-Based Dietary Guidelines. SAJCN: 14:3

[25]Grujic, V., Martinov-Cvejin, M., Ac-Nikoloic, E. \&NiciforovicSurkovic, O. (2005). Epidemiology of Obesity in Adult Population of Vojvodina. Medical Pregl, 58(5-6): 292-5. http://dx.doi.org/10.2298/MPNS0506292G.

[26] Hester, H., Voster, J., Lesley, T., Bourne, P., Venter, D. \&Oosthuizen, W. (1999). Contribution of Nutrition to the Health Transition in Developing Countries: Framework for Research and Intervention. Nutrition Science Policy: 341-349.

[27] Kamandjeu, R.M., Edwards, R., Atanga, J.S., Kiawi, E.C., Unwin, N. \&Mbanya, J-C. (2006). Anthropometry Measures and Prevalence of Obesity in the Urban Adult Population of Cameroon: an Update from the Cameroon Burden of Diabetes Baseline Survey. BMC Public Health, 6:228-1471. http://dx.doi.org/10.1186/1471-2458-6-228.

[28] Kara, K. (2004). Obesity epidemic in Africa. International Association for the Study of Obesity.

[29]Kartikeyan, S. \&Nagaonkar, S.N. (2002). Tackling Obesity among Employees: Role of the Industrial Physician. Indian Journal of Occupational and Environmental Medicine, 6(2): 94-8.

[30]Kruger, H.S., Puoane, T., Senekal, M. \& van der Merwe, M-T. (2005) Obesity in South Africa: Challenges for Government and Health Professionals. Public Health Nutrition: 8(5), 491-500. http://dx.doi.org/10.1079/PHN2005785.

[31] Lambert, E.V., Bohlmann, I. \& Kolbe-Alexander, T. (2001). '’Be Active', Physical Activity for Health in South Africa. South African Jounal of Clinical Nutrition, 14: 12-16.

[32]Lee, R.D. \&Nieman, D.C. (2003). Nutrition Assesment. London: McGraw.

[33]Levitt, N.S., Katzenellenbogen, J.M., Bradshaw, D., Hoffman, M.N. \&Bonnici, F. (1993). The Prevalence and Risk Factors for NIDDM in Urban Africans in Cape Town, South Africa. Diabetes Care: 16(4): 601-7. http://dx.doi.org/10.2337/diacare.16.4.601.

[34]Levitt, N.S., Steyn, K., Lambert, E.V., Fourie, J.M. \&Rossouw, K. (1999). Modifiable Risk Factors for Type1 Diabetes Mellitus in a Peri-Urban Community in South Africa. Diabetic Medicine: 16(11): 946-50. http://dx.doi.org/10.1046/j.1464-5491.1999.00185.x.

[35] Mciza, Z., Goedecke, J.H., Steyn, N.P., Charlton, K., Puoane, T., Meltzer, S., Levitt, N.S. \& Lambert, E.V. (2005). Development and Validation of Instruments Measuring Body Image and Body Weight Dissatisfaction in South African Mothers and their Daughters. Public $\begin{array}{lll}\text { Health } & \text { Nutrition: } & \text { 509-519. }\end{array}$ http://dx.doi.org/10.1079/PHN2005814.

[36]Meyer, A-M., Evenson, K.R., Couper, D., Stevens, J., Pereira, M.A \&Heis G. (2008). Television, Physical Activity, Diet and Body Weight Status: the ARIC Cohort. International Journal of Behavioural Nutrition and Physical Activity: 5(68), 1186-1479. http://dx.doi.org/10.1186/1479-5868-5-68. 
[37]Ministry of Health and Social Services, Namibia. (2000). Namibia Demographic and Health Survey. Windhoek: MOHSS.

[38]Ministry of Health and Social Services, (February 2003). Guide Line for Management of Hypertension. Windhoek: MOHSS.

[39]Molarius, A. (2002). The Contribution of Lifestyle Factors to Socioeconomic Differences in Obesity in Men and Women- a PopulationBased Study in Sweden. European Journal of Epidemiology, 18:227 234. http://dx.doi.org/10.1023/A:1023376012627.

[40]Mvo, Z., Dick, J. \&Steyn, K. (1999). Perceptions of Overweight African Women about Acceptable Body Size of Women and Children. Curationis, 22:27-31. http://dx.doi.org/10.4102/curationis.v22i2.719.

[41]New Era (27 March 2007). Online Namibian newspape www.newera.com.na /

[42]Nicklas, B. J., Cesari, M., Penninx, B. W., Kritchevsky, S. B., Pahor M. \& Harris, T. B. (2006). Abdominal Obesity is an Independent Risk Factor for Chronic Heart Failure in Older People. From the Sticht Center on Aging, 54 (3): 413-20.

[43] Office of the President, Namibia. (2004). Namibia Vision 2030: Policy Framework for Long-Term National Development. Windhoek: Office of the President.

[44]O'Keefe, S.J., Marot, N.R., Symmonds, K.L. \& Berger, G.M. (1988) Nutritional Status Dietary Intake and Diseases Patterns in Rural Hereros, Kavangos and Bushmen in South West Africa/ Namibia. South Africa Medical Jounal: 73(11):643-8.

[45] Onandjokwe Hospital Health Information System HIS2K Namibia. (2005). Outpatient Services.

[46]Opie, L.H. (1995). Hypertension. In Fourie J. AND Steyn K. (Eds.) Chronic Diseases and Lifestyle in South Africa. MRC Technical Report.

[47]O'Rahilly, S., Farooqi, I.S., Yeo, G.S.H \& Challis, B.G. (2003). Minireview: Human Obesity-Lessons from Monogenic Disorders. Endocrinology: 144 (9):3757-3764. http://dx.doi.org/10.1210/en.2003-0373.

[48]Pate, R., Pratt, M., Blair, S.N., Haskell, W.L., Macera, C.A., \& Bouchard, C. et al. (1995). Physical Activity and Public Health: A Recommendation from the Centers for Diseases Control and Prevention and the American College of Sport Medicine.

[49]Perbellini L. (2004). Job as a Risk Factor for Obesity and the Contrary Med Lav. 95: 211-222.

[50]Pollack, K.M., Sorock, G.S.,Slade, M.D., Cantley, L., Sircar, K., Taiwo, O. \& Cullen, M.R, (2007). Association between Body Mass Index and Acute Traumatic Workplace Injury in Hourly Manufacturing Employees. American Journal of Epidemiology, 166 (2): 204-211. http://dx.doi.org/10.1093/aje/kwm058.

[51] Popkin, B.M. (2001). The Nutrition Transition and Obesity in the Developing World. Jounal of Nutrition: (131): 871-873.

[52]Popkin, B.M. (2004). The Nutrition Transition: an Overview of World Patterns of Change. Nutrition Review, 62(7): 140-3 http://dx.doi.org/10.1301/nr.2004.jul.S140-S143.

[53] Popkin, B.M., Horton, S.H. \& Kim, S. (2001). The Nutrition Transition and Prevention of Diet-related Diseases in Asia and the Pacific. Canada: United Nations University Press

[54]Puoane, T., Blandley, H. \& Hughes, G. D. (2005). Obesity among Black South African Women. Human Ecology Special Issue, 13: 91 95.

[55]Puoane, T., Fourie, J.M., Shapiro, M., Rosling, L., Tshaka, N.C. \&Oelefse, A. (2005). Big is Beautiful- an Exploration with Urban Black Community Health Workers in a South African Township South African Jounal of Clinical Nutrition, 18(1): 6-15.

[56]Puoane T, Steyn K, Brandshaw D, Laubscher R, Fourie J, Lambert V, Mbananga N. (2002). The South African and Demographic and Health Survey. Obesity Research, 10: 1038-1048. http://dx.doi.org/10.1038/oby.2002.141.

[57]Puoane, T. \&Tsolekile, L. (2008). Challenges Faced by the Black South Africans in the Prevention of Non-Communicable Diseases. Tribes and Tribals, Special Volume, 2: 9-14.

[58]Raja, K. (2005). Chronic Diseases will kill 35 million in 2005. Geneva: Third World Network.

[59]Sobngwi, E., Mbanya, J-C.N., Kengne, A.P., Fezeu, L., Minkoulou, M., Aspray, T.J. \&Alberti, K.G.M.M. (2002). Physical Activity and its Relationship with Obesity, Hypertension and Diabetes in Urban and Rural Cameroon. International Jounal of Obesity: 26(7):1009-1016.

[60]Soteriades, E.S., Hauser, R., Kawachi, I., Dimitros, L., Christian, C.D \& Kales, N.K, (2005). Obesity and Cardiovascular Diseases. Obesity Research, 13:1756-1763. http://dx.doi.org/10.1038/oby.2005.214.

[61]Standler, K. (2006). Dietary Intake, Physical Activity and Risk for Chronic Diseases of Lifestyle Among Employees at a South African Open-Cast Diamond Mine. Cape Town: Stellenbosch University

[62]Steyn, K., Kazellenbogen, J. M., Lombard, C. J. \& Bourne, L.T. (1997). Programme for Chronic Disease of Lifestyle, Journal Cardio- vascular Risk, 4 (2): 135-42. http://dx.doi.org/10.1097/00043798 199704000-00010.

[63]Steyn, N. P., Senekal, M., Brits, S., Alberts, M., Mashengo, T. \&Nel, J. H. (2000). Weight and Health Status of Black Female Students. South Africa Medical Jounal, 90 (2): 146-52.

[64]Stockmeyer, C., Kuester, S., Ramsey, D. \& Dietz. (2001). National Nutrition Summit, May 30, 2000: Results of the Obesity Discussion Groups. Obesity Research: 9: 41S. http://dx.doi.org/10.1038/oby.2001.34

[65] Tucker L. A. \& Clegg A.G. (2002). Differences in Health Care Costs and Utilisation among Adults with Selected Lifestyle-Related Risk Factors. AM J Health Promotion, 16:225-233. http://dx.doi.org/10.4278/0890-1171-16.4.225.

[66] Voster, H.H., Bourne, L.T., Venter, C.S. \&Oosthuizen, W. (1999). Contribution of Nutrition to the Health Transition in Developing Countries: A Framework for Research and Intervention. Nutrition Science Policy: 341-349.

[67]Wildschutt, P.J. (2005). The effect of Accumulative Physical Activity on the Fitness and Health Status of Rural School Children. Cape Town: University of the Western Cape.

[68] World Health Organization. (1995). Physical Status: the Use and Interpretation of Anthropometry. Geneva: WHO

[69]World Health Organization, (2002). World Health Report 2002. Reducing Risks, Promoting Healthy Lifestyles. Geneva: WHO.

[70]World Health Organization, (2003). WHO Global Strategy on diet, physical activity and health: African Regional Consultation Meeting Report Harare, Zimbabwe, 18-20 March 2003. Geneva: WHO.

[71]WHO Technical Report Series. (2002). the problem of Overweight and Obesity: Preventing and Managing the Global Epidemic. Report of a WHO Consultation. Geneva, World Health Organization.

[72] WHO Technical Report Series. (2003). Diet, Nutrition and the Prevention of Chronic Diseases. Report of a Joint WHO/FAO Expert Consultation. World Health Organization, Geneva.

[73]WHO. (20 September 2005). Workshop on Obesity Prevention and Control Strategies in the Pacific. [Online], Available: 9 [24/04/07 09:25 am]

[74]W HO. (03 October 2005). Press Release who/2005. Stop the Global Epidemic of Chronic Diseases. [Online], Available: http://www.who.int/entity/mediacenter/news/release/2005/en/ [25/3/07 11:15am]

[75]WHO. (2005). Diabetes Programme. [Online], Available: $\mathrm{http} / / / \mathrm{www}$. who.int/diabetes/facts/world figures/en/index.htm [25/3/07 10:35]

[76]Wolf, A.M. \&Colditz, G.A. (1998). Current Estimates of the Economic Cost of Obesity in the United States. Obesity Research, 6(2): 173-5. http://dx.doi.org/10.1002/j.1550-8528.1998.tb00322.x. 